\title{
TWO TIME SCALES FOR THE PRICE OF ONE (ALMOST)
}

\author{
by Lisa Goddard, James W. Hurrell, Benjamin P. Kirtman, James Murphy, \\ Timothy Stockdale, and Carolina Vera
}

Although differences exist between seasonal- and decadal-scale climate variability,

predictability, and prediction, investment in observations, prediction systems, and decision

systems for either time scale can benefit both.

W hile some might call Decadal Prediction the new kid on the block, it would be better to consider it the latest addition to the Climate Prediction family. Decadal Prediction is the fascinating baby that all wish to talk about, with such great expectations for what she might someday accomplish. Her older brother, Seasonal Prediction, is now less talked about by funding agencies and the research community. Given his capabilities, he might

AFFILIATIONS: GODDARD-International Research Institute for Climate and Society, The Earth Institute of Columbia University, Palisades, New York; HurrelL-National Center for Atmospheric Research, Boulder, Colorado; KIRTMAN-Rosenstiel School of Marine and Atmospheric Science, University of Miami, Miami, Florida; Murphy - Met Office Hadley Centre, Exeter, United Kingdom; StOCKDALE-ECMWF, Reading, United Kingdom; VERA-CIMA/CONICET-Universidad de Buenos Aires/FCEyN, Buenos Aires, Argentina

CORRESPONDING AUTHOR: Lisa Goddard, International Research Institute for Climate and Society, The Earth Institute of Columbia University, 6I Route 9W, 228 Monell Bldg., Palisades, NY 10964-8000

E-mail: goddard@iri.columbia.edu

The abstract for this article can be found in this issue, following the table of contents.

DOI:10.1175/BAMS-D-II-00220.I

In final form 27 November 2011

(C2012 American Meteorological Society seem mature enough to take care of himself, but in reality he is still just an adolescent and has yet to reach his full potential. Much of what he has learned so far, however, can be passed to his baby sister. Decadal could grow up faster than Seasonal did because she has the benefit of her older brother's experiences. They have similar needs and participate in similar activities, and thus to the extent that they can learn from each other, their maturation is in some ways a mutually reinforcing process. And, while the attention that Decadal brings to the household might seem to distract from Seasonal, the presence of a sibling is actually healthy for Seasonal because it draws attention to the need for and use of climate information, which can bring funding and new research to strengthen the whole Climate Prediction family.

Just as if these were children, it will take an entire community, actually several communities, together with patience and dedication, to evolve and test seasonal and decadal prediction and determine and realize their potentials. Strong and healthy prediction systems are developed only by substantial investment, as are effective decision systems that can make use of them. In this essay, we argue that investments in observations, modeling, and research focused on either time scale benefit both.

Important differences do exist between decadaland seasonal-scale climate variability, predictability, and prediction. First, and most obvious, there is the 
time scale. Seasonal prediction covers the next month to a year into the future and presents the information in terms of monthly or seasonal means. Decadal predictions, which are currently experimental, are being run 10 years into the future, and the information is being viewed mostly as annual to decadal averages. Second, the climate processes and/or phenomena that drive the variability on different time scales are different. For seasonal climate, the dominant driver is the El Niño-Southern Oscillation (ENSO) phenomenon. Variability in the tropical oceans outside the Pacific is important for regional climate variability, although ENSO can influence the Indian Ocean and tropical Atlantic Ocean variability also. For decadal-scale climate variability, the main oceanic drivers appear to sit in the midlatitude oceans; Pacific decadal variability (PDV) and Atlantic multidecadal variability (AMV) have their largest sea surface temperature (SST) expression outside the tropics, and this SST variability may be linked to much deeper oceanic processes compared to ENSO. However, the decadal patterns of decadal variability do extend into the tropical oceans, and it may be that much of their impact is communicated to the atmosphere through these tropical SST changes. In addition, the secular response to man-made changes in atmospheric composition (i.e., greenhouse gases and aerosols) is an important source of predictability on the decadal time scale, but less so on the seasonal time scale. ${ }^{1}$ Finally, the decisions affected are different. Seasonal predictions are more relevant to management decisions, whereas decadal predictions could be useful to planning decisions.

So, how is it that two vastly different time scales could work so well together in a climate services and research perspective? Despite the obvious differences, there are also common, even complementary, elements. Where the synergy is greatest between seasonal predictions and the burgeoning research on decadal predictions is through their dependence on forecast systems. Both prediction efforts use the same type of general circulation models, and they make use of the same global observing systems. Beyond these common priority elements, however, a number of other aspects exist for which past, present, and future investments aimed at one time scale could benefit the other.

COMMON PRIORITIES. The need for adequate observational networks and improved dynamical models appears in almost every recommendation list related to predictive information that one is likely to encounter. Prediction systems are based on observations, models, and their connection through assimilation systems. The three together is the threelegged chair of prediction systems (NRC 2010). Any weak leg compromises the system, and improvements in one leg often lead to improvements in the other legs. Recent advances in ENSO prediction skill at the European Centre for Medium-Range Weather Forecasts (ECMWF) were accomplished by both improvements to their model and improvements to the ocean data assimilation system (Balmaseda et al. 2010). Additionally, hindcasts from the ECMWF forecast system have demonstrated the value of the Tropical Atmosphere Ocean (TAO) array of data buoys in the tropical Pacific Ocean; a dramatic drop in ENSO forecast error coincides with the completion of the array in the early 1990s (Stockdale et al. 2011). This error reduction is largest for forecasts initiated in February, when model biases in their model are minimum. This reveals the connections between these three elements of forecast systems: observations and their assimilation into models are crucial for prediction, but better models better elucidate the value of the observing network.

The quality of predictive climate information depends on the quality of models. Models are far from perfect in their discretized, parameterized representation of the climate system. Long-term commitment of resources to model and assimilation system development will pay off with improved climate information on all time scales. In order to address longstanding systematic model errors, the community needs to improve the diagnosis of key physical processes contributing to these errors (Jakob 2010). Many of the mean biases and variability biases that hamper predictions appear within the first few hours or days of the forecast; for example, characteristics like the diurnal cycle, important in warm-season precipitation, are often not well represented. Indeed, it is critical that our climate prediction systems simulate the statistics of regional weather with fidelity given that the upscaling of that weather becomes the seasonalto-decadal mean and also that the weather characteristics (e.g., changing precipitation intensity or frequency) determine many of the impacts. To better represent the temporal characteristics of the climate, forecast systems must be developed and tested across a range of time scales, which also brings the potential for stronger collaboration between the weather and climate prediction communities (Hurrell et al. 2009).

${ }^{1}$ When they occur, the impacts of explosive volcanic eruptions are important on both seasonal and multiannual time scales. 
Furthermore, the development of climate models with better horizontal and vertical resolution should be a priority in order to improve the representation of coupled ocean-atmosphere variability (Guilyardi et al. 2004) and stratospheric effects on surface and tropospheric climate anomalies (Baldwin and Dunkerton 2001; Ineson and Scaife 2009). A priority is to implement the recommendations from the World Modeling Summit for Climate Prediction (Shukla et al. 2009), which calls for dedicated computational facilities 1,000-10,000 times more powerful than available today in order to address these issues.

Improvements of models and assimilation systems cannot proceed without an adequate observational network. The Global Climate Observing System (GCOS), including its many ocean and land components, is essential for improving seasonal prediction and developing decadal prediction. Real-time, complete observations provide the initial conditions to the predictions, and long, stable histories of ocean, atmosphere, and terrestrial climate that are necessary to verify the models' ability to make predictions. The observational network, originally designed for weather prediction, is only recently coming to grips with the additional requirements to collect, integrate, and sustain quality observations for climate time scales, but such a climate observing system is still far from being realized (GCOS 2010).

Individual observations-localized snapshots of the climate-have limited value until those data are integrated into the big picture that can be used for monitoring, initialization and/or verification of predictions, and diagnostic validation of models. Improved methods of analyzing the observations and assimilating them into climate models, including treatment of nonstationary observing systems, ${ }^{2}$ would benefit research and prediction and provide a more stable monitoring platform for climate variability and change. Whether we consider salinity measurements in the open ocean or rain gauge data in most of the developing world, many climate data records are short relative to the long periods over which we need to test models. Ways of procuring and protecting climate observing systems are urgently needed. Additionally needed are increased international coordination on data handling standards and mutually applied methodologies to assemble, quality-check, reprocess, and reanalyze datasets, and to estimate their uncertainties. Such integration should be considered as an essential component of the climate observing system.
Ocean observations are particularly crucial as initial conditions for both seasonal and decadal prediction to obtain the predictability arising from slow changes in ocean circulation or heat content anomalies. Recent improvements to the coverage of the ocean with Argo floats provide unprecedented measurements of subsurface ocean temperature and salinity that are particularly relevant to the initialization of decadal predictions. As mentioned before, the TAO array of buoys is essential to the initialization of ENSO predictions and also to real-time monitoring of tropical Pacific variability. This is also important because the improved representation of the evolution of ENSO in models may improve simulation and prediction of Pacific decadal variability (Vimont et al. 2003). Additionally, we must quantify the benefit of satellite data to the initialization of the ocean, sea ice, snow cover, and soil moisture, which leads to information not only on how these elements contribute to seasonal prediction but also on their role in, and response to, decadal-scale variability.

\section{LESSONS FROM SEASONAL PREDICTION RELEVANT TO DECADAL PREDICTION} RESEARCH. Dynamical seasonal prediction systems are operational or quasi operational at a number of forecasting centers around the world (e.g., Saha et al. 2006; Stockdale et al. 2010) and have been since the early 1990s in some cases. Much of the experience gained by the seasonal prediction community over the last couple decades can be applied to decadal prediction. Some of these lessons inform our expectations of what can skillfully be predicted. For example, the prediction time horizon of a phenomenon is shorter than the time scale of the phenomenon. ENSO has a time scale of 3-7 years but is only predictable about 6-12 months in advance, perhaps as much as 18 months for very strong events (Chen et al. 2004). A similar result is emerging for AMV from "perfect model" studies (i.e., prediction experiments in which the model tries to predict itself), where ocean initial conditions may supply 10-15 years of predictability in upper-ocean heat content for certain regions, while the time scale of the variability is 20 years or longer (Branstator and Teng 2010; Msadek et al. 2010). This important aspect of the forecasts must be communicated to people considering the use of decadal predictions. However, while natural climate variability might be the dominant driver of time-varying anomalies out to a decade ahead for some regions, that natural climate

\footnotetext{
${ }^{2}$ Here, "nonstationary observing systems" refers to the geographic relocation of meteorological stations, or the change of instrumentation or technology used to monitor the weather and climate over time.
} 
variability may not be predictable via initialization; in contrast, the slowly developing response to forced climate change, although of smaller magnitude at this time scale, may be predictable, at least in sign (e.g., Lee et al. 2006; Hurrell et al. 2010). Beyond a decade ahead, uncertainty in the response to external forcing becomes increasingly important as a source of prediction error, while decadal variability remains as a significant additional uncertainty, especially at regional scales (Hawkins and Sutton 2009).

Another insight of the seasonal prediction community is that the spatial scales of predictable signals for climate are much larger than the predictable spatial scales for weather. Spatially heterogeneous variability within a regional climate signal represents mainly unpredictable noise of more random, localized processes typically related to weather transients. The spatial scales of predictable climate signals typically increase for longer time scales, suggesting that the predictable spatial scales will be even larger for decadal variability than for seasonal variability. Thus, regional-scale climate information must serve as the basis for interpretation of the local scales at which many decision systems operate. If the regional-scale information is not represented correctly, the localscale information and the associated uncertainty will be meaningless.

The quantitative assessment of predictable time horizons and spatial scales of any given prediction system requires hindcast studies, which are predictions of past variability. Large sets of hindcasts are necessary to estimate skill for both seasonal and decadal predictions, to sample different phases of variability (e.g., active vs quiet periods or positive vs negative anomalies), and to quantify and understand different sources of predictability. For seasonal climate, hindcasts, in combination with forecasts, allow climate scientists to calibrate and correct biases in their forecasts. Hindcasts also allow scientists from other fields and decision makers to assess the potential value of the forecast information. This will be more challenging for decadal prediction where few realizations of decadal variability exist in the instrumental record to test our ability to predict it. This again calls for improved data assimilation methodologies that can make the most of the limited historical data we have (Balmaseda et al. 2010).

All relevant data, including observations, hindcasts, and forecasts, must be publically accessible for researchers and decision makers to benefit from it. Ideally the data would be accompanied by information on how to interpret and use the data, and perhaps what might constitute its misuse. It has been demonstrated in a number of cases that greater access to data leads to wider use of the information, such as the availability of long model hindcasts from the Development of a European Multimodel Ensemble System for Seasonal-to-Interannual Prediction (DEMETER; see www.ecmwf.int/research/demeter) (e.g., Palmer et al. 2004), and long simulation and hindcast runs from the Coupled Model Intercomparison Project phase 3 (CMIP3; Meehl et al. 2007) of the World Climate Research Programme (WCRP). Coordinated sets of decadal prediction hindcasts, such as those from ENSEMBLE-based predictions of climate changes and their impacts (ENSEMBLES; http://ensembles-eu.metoffice.com, are beginning to become available (van der Linden and Mitchell 2009) and will be part of the Fifth Assessment Report of the Intergovernmental Panel on Climate Change (IPCC AR5), but in order to interpret those data, one will also need access to relevant observations for bias correction and verification. Insufficient data access does remain an obstacle to wider use of the predictions. The World Meteorological Organization has designated a lead center of global producing centers www.wmo.int/pages/prog/wcp/wcasp clips/producers_forecasts.htm), but those data are not openly available, and hindcast data are not available from several of the prediction systems that participate. On the other hand, the Working Group on Seasonal to Interannual Prediction (WGSIP) of the WCRP is currently coordinating the ClimateSystem Historical Forecast Project (CHFP), which will provide access to a wide range of hindcasts to evaluate subseasonal-to-decadal predictions of the climate system (Kirtman and Pirani 2009).

Additional important lessons that have been realized in the seasonal prediction community include the following: 1) forecasts must be issued probabilistically and require ensemble sizes that are commensurate with signal-to-noise levels of the temporal and spatial scales being predicted; 2) forecast quality must be assessed through a suite of metrics, as no single metric can cover all aspects of a forecast relevant to users (e.g., Jolliffe and Stephenson 2003; Hurrell et al. 2010); and 3) the climate system exhibits conditional skill (e.g., Goddard and Dilley 2005; Collins et al. 2006) and identification of the times when forecasts are likely to be more accurate leads to better decision systems (Goddard et al. 2010). These lessons are widely recognized in the seasonal prediction community, and they will apply to decadal predictions too.

The systematic use of seasonal prediction information is much less developed than the predictions 
themselves. In part this is because the prediction information evolved independently from its application. We now know that the content and format of the information required can be quite varied from sector to sector or even between regions for a given sector. While those who apply the climate information cannot determine the science just based on demand, their concerns, needs, and understanding of the information can inform where investment and communication of the science will have the greatest impact. Since considerable research and development is required to better incorporate climate information into decision systems, we will return to that as a point of investment in the future. The main lesson here is that there appears to be value in the cooperation between scientists and decision makers in developing decision systems for climate risk management.

INVESTMENTS IN SEASONAL PREDICTION THAT WILL BENEFIT DECADAL PREDICTION RESEARCH. Although seasonal prediction is a relatively mature practice, significant room for improvement remains. Continued investments in prediction techniques, including improvement to variability diagnostics and to the representation of interactions between climate system components, are necessary. This research can also advance decadal prediction. Additionally, climate information often must be quantitatively practical and meaningful at the scales on which decisions will be made. Approaches such as statistical downscaling of information in space and/or time or the transformation of coarser-scale climate information into other climate-related variables (flood risk, dry spells, maize yield, etc.) that are more congruent with societal concerns must be tested first in the seasonal prediction arena.

As stated early on, improved dynamical models is a common priority of climate prediction at all time scales. While work to improve dynamical models, which benefits all climate prediction time scales, is in progress, care and resources should be given to the estimation of quality and uncertainty, including allowance for model error, of existing forecast systems. Reliable estimates of uncertainty allow decision makers to account properly for risk. Given inevitable uncertainties in model predictions, the development of ensemble techniques to realistically sample the consequences of initial state and model errors is important. Decadal predictions will additionally require estimates of the anthropogenic contributions to forecast uncertainty and skill. The techniques that will allow us to estimate uncertainty for the whole range of climate prediction time scales will likely be developed in the context of seasonal prediction.

As a complement to prediction research, empirical and diagnostic studies of interannual climate variability must continue. Some aspects of ENSO are still not well understood, such as the interevent variability and why models fail to capture it. This includes the apparent decadal variability in the magnitude and frequency of ENSO events. It is thought that ENSO events can drive PDV through the atmospheric bridge (Alexander et al. 2002). However, it is primarily the ENSO events that exhibit the strongest SST anomalies in the central Pacific appear to drive aspects of PDV (Di Lorenzo et al. 2008). Improved understanding and better predictability of the details of ENSO events and their role(s) in PDV requires more investigation.

Improved climate predictions are of limited value to society, however, if that information cannot be readily incorporated into decision systems. Investment in collaboration and pilot projects that bring together researchers and decision makers with the diverse expertise necessary to design and implement such systems can yield benefits beyond the specific project. First, such projects build closer ties between the climate prediction specialists and other scientists and decision makers. This builds trust and better understanding of climate information, as well as increases the climate scientists' understanding of information needs and decision contexts. If this begins with seasonal prediction, there is opportunity to demonstrate performance over the recent past, through a feasible time frame in the present, and over the next few years. Building these relationships takes time, but the results can be realized in only a matter of years, rather than decades. As more information becomes available on decadal variability, these relationships can pay dividends through better communication and understanding, creating networks to develop useable information. Second, well-documented pilot projects (e.g., Brown et al. 2009; Ceccato et al. 2010) can inform other decision systems to allow climate risk to be managed more effectively by example, which increases the uptake of climate information, and can also guide the development, format, and delivery of climate information. The outcomes of pilot projects can be particularly beneficial to both the research community and other decision makers if they document the pitfalls and difficulties, not just the benefits, of using climate information. Third, to the extent that the increased uptake of climate prediction improves climate risk management at seasonal time scales, it will indirectly 
strengthen the capacity for using climate information on longer time scales.

In order to impact risk management, or to be realistically assessed by pilot projects, climate information must be supplied at appropriate spatial and temporal scales, address the appropriate variable(s), and contain reliable estimates of uncertainty. In most cases that information derives from regional-scale changes in the climate, at which the predictable climate signals at seasonal-to-decadal time scales operate; examples include worldwide teleconnection patterns associated with El Niño and La Niña events or the robust features of global warming. Thus, although localscale information may be desired, it becomes more relevant within the large-scale context. The large scale carries both predictability and uncertainty, but downscaling to local scales, while potentially adding useful detail, contributes mainly to the uncertainty. This point is more easily demonstrated for seasonal prediction where, for example, forecasts for summer precipitation are made and can be verified each year at local to regional spatial scales (e.g., Gong et al. 2003). Examination of the spatial variation of local climate variability within the regional-scale climate signal becomes both an educational opportunity and a point for cooperative information development. The importance of this perspective will be even greater for decadal variability, however, where the predictable scales are likely to be larger, but the strength of the signal is likely to be smaller.

INVESTMENTS TOWARD DECADAL PREDICTION THAT WILL BENEFIT SEASONAL PREDICTION. The knowledge that global surface temperatures will continue to rise over the next several decades under any plausible emission scenario (Solomon et al. 2007) is now a factor in the planning of many organizations and governments. We know that climate changes will not be uniform around the globe, and natural regional and seasonal variations will have large impacts, especially over the next few decades or less. An important challenge, therefore, is to predict regional-scale climate variability and change. The decadal time scale is also widely recognized as an important time scale for endeavors such as water, agricultural, and land use planning (e.g., Vera et al. 2010).

The promise of decadal climate prediction is supported by observational evidence of decadal climate variability with significant regional impacts, the effects of anthropogenic and naturally forced climate change, evidence of potential skill from idealized predictability studies (Collins et al. 2006; Boer 2011), and pioneering attempts at predictions obtained by initializing climate models with observations (Smith et al. 2007). A number of efforts are underway, including internationally coordinated experiments of initialized decadal predictions (WCRP/CMIP5; Taylor et al. 2009) that are contributing to the IPCC AR5, and several national initiatives to provide decadal-scale climate information. However, many formidable challenges need to be addressed to build practical prediction systems capable of credible, useful decadal-scale information at regional scales (e.g., Murphy et al. 2010). The investments necessary to address many of these challenges can benefit seasonal prediction also.

Investments toward the prediction hindcast experiments will directly benefit seasonal as well as decadal prediction efforts. These are the first generation of decadal prediction hindcasts. Since, as discussed above, large sets of hindcasts are required to assess the quality of prediction systems, and since our ocean observations are limited going back into the twentieth century, production of decadal hindcasts will require innovative approaches to data assimilation and ocean-state estimation (Balmaseda et al. 2010). The assimilation methodology will be useful to extending seasonal prediction hindcasts further back in time, and also to improving initialization techniques going forward. Meanwhile, hindcasts generated by these efforts will be mutually beneficial. Decadal predictions already will predict the next season to a year on their way to prediction of the decade, thus increasing the suite of hindcasts for seasonal prediction. Seasonal predictions, and their hindcasts, could easily be extended further out into the future, which would increase the suite of experimental hindcasts for decadal prediction.

As we research decadal variability and the potential for prediction, we gain a better understanding and quantification of the role of longer-term variability in year-to-year impacts. Such understanding can be valuable to resource management in the face of longer-term expectations and planning, particularly in instances where the decadal-scale variations of the background climate modify the risk of exceeding certain climate thresholds or the frequency of extremes. A better understanding of some of the processes important for forcing decadal variability, and their improved representation in forecast models, also helps increase the quality of our seasonal forecasts. As discussed previously, better understanding of PDV and AMV is needed, including interactions with ENSO, and impacts on remote regions via teleconnections. Additional phenomena hypothesized to be 
sources of decadal predictability, such as the response to solar variability in the Pacific region or the thermodynamic influence of persistent upper-ocean heat content anomalies worldwide (Meehl et al.2009), may also be important sources of regional predictability on seasonal time scales.

Decadal prediction has received much attention at least in part because of the high visibility and politicization of climate change projections. The fact that, over the span of a decade or two, variability may dominate anthropogenic trends regionally leads the climate risk management community to seek out decadal-scale climate information. Often "variability" is less politically charged than "change" and thus may represent a more desirable investment to some. Allowance for both the physical and political realities opens the door to adaptation that includes wise planning for the coming decade(s) and also preparation for year-to-year variability, which is where the largest impacts are most often experienced. Often resource management decisions are constrained by policy (Rayner et al. 2005), but since decadal variability and climate change are relatively new considerations for lawmakers, policy may be less restrictive for the longer-time-scale decisions. Thus, increased action and uptake of climate information on longer time scales may actually allow for policy reform that could make it less difficult for action on seasonal climate information. This of course assumes that the experience with longer-time-scale information leads to the perception of beneficial outcomes that resulted from the use of that information, and the most effective path to that is again the cooperative development of knowledge and decision systems (Lemos and Morehouse 2005).

CONCLUSIONS. The investments described will take considerable human and financial resources and a commitment to sustain them. Compared to the costs of adaptation, the costs of implementing these recommendations will be low, but substantial enough to highlight the need for international coordination to minimize duplication and share the lessons learned throughout the communities involved. These are actions that would be prudent even in the absence of climate change. However, given that climate change has focused global attention on the need for climate information, climate services could build adaptation incrementally through better awareness, preparedness, and resiliency to climate variability at all time scales.

Seasonal and Decadal should not be treated as competitors for the attention of the scientific community. Rather, we should enable them to "play nicely" together, in order to maximize the efforts invested in each.

ACKNOWLEDGMENTS. This essay grew out of white papers solicited by the World Climate Conference 3 for the expert sessions on seasonal prediction and decadal prediction. We gratefully acknowledge the input and perspectives of all our contributing authors: Y. Aitchellouche, O. Alves, W. Baethgen, M. Barange, G. Boer, M. Deque, M. Dettinger, Y. Ding, O. P. Dube, R. Graham, D. Griggs, P. Hayman, M. Kadi, V. Kattsov, N. Keenlyside, M. Kimoto, N. Kobysheva, A. Kumar, K. Kumar, W. Landman, R. Martínez, S. Mason, G. Meehl, V. Mehta, H. Meinke, P. Nobre, E. Odada, S. Parey, H. Pohlmann, J. Polovina, G. Poveda, A. Scaife, B. Seguin, D. Smith, O. Tomoaki, K. Trenberth, and W. T. Yun. We also thank Jeff Rosenfeld for his thoughtful suggestions on this essay.

\section{REFERENCES}

Alexander, M. A., I. Bladé, M. Newman, J. R. Lanzante, N.-C. Lau, and J. D. Scott, 2002: The atmospheric bridge: The influence of ENSO teleconnections on air-sea interaction over the global oceans. J. Climate, 15, 2205-2231.

Baldwin, M. P., and T. J. Dunkerton, 2001: Stratospheric harbingers of anomalous weather regimes. Science, 294, 581-584.

Balmaseda, M. A., and Coauthors, cited 2010: Initialization for seasonal and decadal forecasts. [Available online at www.oceanobs09.net/blog/?p=5.]

Boer, G. J., 2011: Decadal potential predictability of twenty-first century climate. Climate Dyn., 36, 1119-1133, doi:10.1007/s00382-010-0747-9.

Branstator, G., and H. Teng, 2010: Two limits of initialvalue decadal predictability in a CGCM. J. Climate, 23, 6292-6311.

Brown, C., E. Conrad, A. Sankarasubramanian, S. Someshwar, and D. Elazegui, 2009: The use of seasonal climate forecasts within a shared reservoir system: The case of Angat reservoir, the Philippines. Climate Change Adaptation in the Water Sector, F. Ludwig et al., Eds., Earthscan, 249-264.

Ceccato, P., I. N. S. Jaya, J. H. Qian, M. K. Tippett, A. W. Robertson, and S. Someshwar, 2010: Early warning and response to fires in Kalamantan, Indonesia. IRI Tech. Rep. TR10-14, 22 pp. [Available online at http:// iri.columbia.edu/publications/id=1037]

Chen, D., M. A. Cane, A. Kaplan, S. E. Zebiak, and D. Huang, 2004: Predictability of El Niño over the past 148 years. Nature, 428, 733-736, doi:10.1038/ nature 02439 . 
Collins, M., and Coauthors, 2006: Interannual to decadal climate predictability in the North Atlantic: A multimodel-ensemble study. J. Climate, 19, 1195-1203.

Di Lorenzo, E., and Coauthors, 2008: North Pacific Gyre Oscillation links ocean climate and ecosystem change. Geophys. Res. Lett., 35, L08607, doi:10.1029/2007GL032838.

GCOS, 2010: Implementation plan for the Global Observing System for climate in support of the UNFCCC. WMO Rep. GCOS-138 (GOOS-184, GTOS-76, WMO/ TD-1523), 180 pp. [Available online at www.wmo.int pages/prog/gcos/Publication/gcos-138.pdf.]

Goddard, L., and M. Dilley, 2005: El Niño: Catastrophe or opportunity. J. Climate, 18, 651-665.

- , and Coauthors, 2010: Providing seasonalto-interannual climate information for risk management and decision-making. Procedia Environ. Sci., 1, 81-101, doi:10.1016/j.proenv.2010.09.007.

Gong, X., A. G. Barnston, and M. N. Ward, 2003: The effect of spatial aggregation on the skill of seasonal precipitation forecasts. J. Climate, 16, 3059-3071.

Guilyardi, E., and Coauthors, 2004: Representing El Niño in coupled ocean-atmosphere GCMs: The dominant role of the atmospheric component. J. Climate, 17, 4623-4629.

Hawkins, E., and R. Sutton, 2009: The potential to narrow uncertainty in regional climate predictions. Bull. Amer. Meteor. Soc., 90, 1095-1107.

Hurrell, J. W., G. A. Meehl, D. Bader, T. L. Delworth, B. Kirtman, and B. Wielicki, 2009: A unified modeling approach to climate system prediction. Bull. Amer. Meteor. Soc., 90, 1819-1832.

_ , and Coauthors, 2010: Decadal climate prediction: Opportunities and challenges, Proceedings of OceanObs'09: Sustained Ocean Observations and Information for Society, J. Hall, D. E. Harrison, and D. Stammer, Eds., Vol. 2, ESA Publ. WPP-306, 12 pp., doi:10.5270/OceanObs09.cwp.45.

Ineson, S., and A. A. Scaife, 2009: The role of the stratosphere in the European climate response to El Niño. Nat. Geosci., 2, 32-36.

Jakob, C., 2010: Accelerating progress in global atmospheric model development through improved parameterizations: Challenges, opportunities, and strategies. Bull. Amer. Meteor. Soc., 91, 869-875.

Jolliffe, I. T., and D. B. Stephenson, 2003: Forecast Verification: A Practitioner's Guide in Atmospheric Science. John Wiley and Sons, 240 pp.

Kirtman, B., and A. Pirani, 2009: The state of the art of seasonal prediction: Outcomes and recommendations from the First World Climate Research Program Workshop on Seasonal Prediction. Bull. Amer. Meteor. Soc., 90, 455-458.
Lee, T. C. K., F. W. Zwiers, X. Zhang, and M. Tsao, 2006: Evidence of decadal climate prediction skill resulting from changes in anthropogenic forcing. J. Climate, 19, 5305-5318.

Lemos, M. C., and B. J. Morehouse, 2005: The co-production of science and policy in integrated climate assessments. Global Environ. Change, 15, 57-68.

Meehl, G. A., C. Covey, K. E. Taylor, T. Delworth, R. J. Stouffer, M. Latif, B. McAvaney, and J. F. B. Mitchell, 2007: The WCRP CMIP3 multimodel dataset: A new era in climate change research. Bull. Amer. Meteor. Soc., 88, 1383-1394.

—-, and Coauthors, 2009: Decadal prediction. Bull. Amer. Meteor. Soc., 90, 1467-1465.

Msadek, R., K. W. Dixon, T. L. Delworth, and W. Hurlin, 2010: Assessing the predictability of the Atlantic meridional overturning circulation and associated fingerprints. Geophys. Res. Lett., 37, L19608, doi:10.1029/2010GL044517.

Murphy, J., and Coauthors, 2010: Towards prediction of decadal climate variability and change. Procedia Environ. Sci., 1, 287-304, doi:10.1016/j. proenv.2010.09.018.

NRC, 2010: Assessment of Interseasonal to Interannual Climate Prediction and Predictability. National Academies Press, 182 pp.

Palmer, T. N., and Coauthors, 2004: Development of a European Multimodel Ensemble System for Seasonal-to-Interannual Prediction (DEMETER). Bull. Amer. Meteor. Soc., 85, 853-872.

Rayner, S., D. Lach, and H. Ingram, 2005: Weather forecasts are for wimps: Why water resource managers do not use climate forecasts. Climatic Change, 69, 197-227.

Saha, S., and Coauthors, 2006: The NCEP Climate Forecast System. J. Climate, 19, 3483-3517.

Shukla, J., R. Hagedorn, M. Miller, T. N. Palmer, B. Hoskins, J. Kinter, J. Marotzke, and J. Slingo, 2009: Revolution in climate prediction is both necessary and possible: A declaration at the World Modelling Summit for Climate Prediction. Bull. Amer. Meteor. Soc., 90, 175-178.

Smith, D., S. Cusack, A. Colman, A. Folland, G. Harris, and J. Murphy, 2007: Improved surface temperature prediction for the coming decade from a global circulation model. Science, 317, 796-799.

Solomon, S., D. Qin, M. Manning, M. Marquis, K. Averyt, M. M. B. Tignor, H. L. Miller Jr., and Z. Chen, Eds., 2007: Climate Change 2007: The Physical Science Basis. Cambridge University Press, 996 pp.

Stockdale, T. N., and Coauthors, 2010: Understanding and predicting seasonal-to-interannual climate variability-The producer perspective. 
Procedia Environ. Sci., 1, 55-80, doi:10.1016/j. proenv.2010.09.006.

—-, and Coauthors, 2011: ECMWF Seasonal Forecast System 3 and its prediction of sea surface temperature. Climate Dyn., 37, 455-471, doi:10.1007/s00382010-0947-3.

Taylor, K. E., R. J. Stouffer, and G. A. Meehl, 2009: A summary of the CMIP5 experiment design. PCMDI Rep., 33 pp. [Available online at http://cmip-pcmdi .llnl.gov/cmip5/docs/Taylor_CMIP5_design.pdf]

van der Linden, P., and J. F. B. Mitchell, Eds., 2009: ENSEMBLES: Climate change and its impacts at seasonal, decadal and centennial timescales; Summary of research and results from the ENSEMBLES project.. Met Office Hadley Centre Rep., 160 pp. [Available online at http://ensembles-eu.metoffice.com/docs Ensembles_final_report_Nov09.pdf.]

Vera, C., and Coauthors, 2010: Needs assessment for climate information on decadal timescales and longer. Procedia Environ. Sci., 1, 275-286, doi:10.1016/j. proenv.2010.09.017.

Vimont, D. J., D. S. Battisti, and A. C. Hirst, 2003: The seasonal footprinting mechanism in the CSIRO general circulation models. J. Climate, 16, 2653-2667. 